\title{
LA CREACIÓN EN LA MEMORIA OFICIAL MEXICANA DE UN MODELO DE JUSTICIA PREHISPÁNICA: NEZAHUALCÓYOTL ACOLMIZTLI
}

\author{
Maribel Aguilar \\ Universidad Nacional Autónoma de México \\ nikmati_a@hotmail.com \\ Clementina Battcock \\ Dirección de Estudios Históricos \\ Instituto Nacional de Antropología e Historia \\ cbattcock@yahoo.com.ar
}

Resumen: De entre los múltiples gobernantes prehispánicos del centro de México, sobresale la emblemática figura de Nezahualcóyotl (1402-1472). El modelo ejemplar de justicia que representó se observa claramente en las descripciones de cuatro cronistas de distinta naturaleza: Alonso de Zorita, Juan de Pomar, Fernando de Alva Ixtlilxóchitl y Juan de Torquemada. En consecuencia, en este artículo analizaremos las referidas versiones con el objetivo de desentrañar el germen de un futuro héroe patrio. Si bien las características que en este primer momento, siglos XVI y XVII, colocaron a Nezahualcóyotl como un gobernante ejemplar, en tiempos posteriores cambiarán, pero no el modelo prototípico que representó.

Palabras clave: Nezahualcóyotl, Tetzcoco, México Prehispánico, Justicia, Memoria

\begin{abstract}
Between the many preHispanic rulers from central Mexico, stands out the emblematic figure of Nezahualcoyotl (1402-1472). The exemplary model of justice that represented is clearly seen in the descriptions of four chroniclers of different nature: Alonso de Zorita, Juan de Pomar, Fernando de Alva Ixtlilxochitl and Juan de Torquemada. Therefore, in this article we will discuss the aforementioned versions in order to unravel the germ of a future national hero. Even though, the characteristics about this first moment, from the sixteenth and seventeenth centuries, placed Nezahualcoyotl as an exemplary ruler, in later times them will change, but not the prototypical model represented.
\end{abstract}

Keywords: Nezahualcóyotl, Tetzcoco, Prehispanic Mexico, Justice, Memory 


\section{Introducción}

Extremadamente difícil y no menos prolija es la tarea de desenterrar de las fuentes novohispanas descripciones sobre la concepción de justicia que pudieron tener los antiguos grupos prehispánicos. De hecho, en este como en otros temas, es inevitable que pisemos sobre arenas movedizas, en principio, porque los autores que registraron alguna información respecto del universo legal indígena siempre tuvieron por destinatario a un lector ajeno a la realidad del "Nuevo Mundo", y para que éste la comprendiera, tenían que "traducirla" en términos y unidades comprensibles, esto es, enmarcar los relatos en los esquemas o moldes mentales europeos. Así ocurrió con el mundo natural de América y, por supuesto, con las instituciones y creaciones culturales de sus pueblos, por ejemplo, con la justicia. Si bien es indiscutible que los antiguos grupos prehispánicos se rigieron por una normatividad, es difícil precisar fielmente su naturaleza y el modo en que operaba, pues, como se dijo antes, las noticias que hay sobre ella son fragmentarias y las que nos han llegado están impregnadas o han sido filtradas por el contexto, las preocupaciones y la modalidad del registro novohispano. Para atender a este problema es preciso recurrir a la siguiente reflexión de Edmundo O’Gorman: “¿Qué es lo que el hombre ha pensado de sí mismo? [...] todo lo que ha pensado a ese respecto está condicionado, valga la expresión, por la historia. Por eso tiene sentido decir que la historia resulta definitoria del hombre. Por necesidad constitutiva de su ser el hombre siempre ha contado su pasado" (2007, p. 31). De esta manera, 
los autores de las crónicas presentan una conciencia histórica de su tiempo que permea a los procesos históricos anteriores de los que dan testimonio y, por supuesto, a la figura de los personajes que intervienen en ellos.

Hechas las advertencias necesarias, a continuación nos proponemos examinar el "paradigma de justicia y rectitud" representado por el séptimo gobernante tetzcocano, Nezahualcóyotl Acolmiztli (1402-1472), cuyo gobierno tuvo lugar durante el periodo Poclásico Tardío mesoamericano (1200-1520), y participó de la Excan Tlatoloyan o Triple Alianza que conformó junto a los señoríos de Tenochtitlán y Tlacopan (Herrera Maza, López Austin, \& Martínez Baracs, 2013, pp. 835). Esta información proviene de obras historiográficas cuyo origen, perspectivas y motivaciones son diversas, entre ellas las de un magistrado español: Alonso de Zorita, dos escritores mestizos: Juan de Pomar y Fernando de Alva Ixtlilxóchitl y un cronista franciscano: Juan de Torquemada. Al respecto, es necesario reiterar que dentro de esta heterogeneidad de miradas, se entreveran tres planos temporales distintos: el pasado prehispánico objeto de la narración, el presente novohispano de los narradores y nuestro presente (O Gorman, 2007, pp. 34-35). No obstante, en estas fuentes existe una general coincidencia en ellas en cuanto a considerar la imagen de Nezahualcóyotl como una figura ejemplar de soberano y juez. 


\section{El gobernante y su tribunal}

Alonso de Zorita fue oidor en Nueva España en una fase crucial de transformación política que en 1556 Felipe II echó a andar para impedir la explotación de los indios, reducir los tributos y regular el carácter hereditario de las encomiendas (Ahrndt, 1999, vol. I, p.22-23). En la medida en que este proyecto buscaba frenar los excesos de los encomenderos y favorecer a los naturales, frecuentemente se le asocia a las ideas lascasianas, aunque la idea es discutible. Como sea, en su calidad de juez de la Audiencia, a Zorita le competía supervisar la implementación de la nueva normatividad, razón por la cual tuvo un trato cercano con todo género de litigantes indígenas, a los que trató de cerca; este conocimiento, que podríamos llamar de primera mano, fue luego trasladado a su ulterior obra Relación de la Nueva España (Zorita, 1999). Sin embargo, como señala algún autor, aparentemente don Alonso a veces no comprendió, en otros casos tergiversó y en algunos más simplificó determinados conceptos plasmados en la lengua náhuatl, sobre todo los referentes a la supuesta "propiedad" y "estratificación social indígena" (Ruíz Medrano, 1999, vol. I, p. 62). De ahí que su Relación deba ser analizada con cautela y con un agudo ojo crítico, no sólo por los errores lingüísticos y conceptuales en los que incurrió, sino también teniendo a la vista los posibles intereses particulares o institucionales que guiaron su relato; es decir, su personal posición político-social como oficial del rey, contrapuesto a los encomenderos y abiertamente favorable a los proyectos de los frailes franciscanos. 
Por otro lado, no es finalidad de este trabajo adentrarse en el análisis de las conductas delictivas o en el sistema penal de los antiguos nahuas del centro de México, pero si así fuese, la Relación de Zorita no sería precisamente de gran utilidad, pues la información que aporta sobre este tema es más bien escueta, vaga o general. Tales vacíos, naturalmente, dan pie a hacer conjeturas o especulaciones sobre la auténtica naturaleza del delito en el mundo indígena y sobre el tipo de sanciones o castigos aplicados a los infractores. Pero, con todo, aun es posible hacerse algunas ideas superficiales sobre la noción y el sentido de la ley en Mesoamérica.

En cuanto al espectro de la justicia prehispánica que se forjó Zorita, de las tres grandes sedes de poder de la cuenca de México: Tenochtitlan, Tlacopan y Tetzcoco, esta última era para él la de mayor peso. Y lo era porque en ella se estableció, concentró e irradió el buen orden y las leyes, una labor cuyo mérito indiscutible correspondió a Nezahualcóyotl. Bajo su gobierno de 42 largos años, hizo gala de un lúcido razonamiento y una gran templanza en su papel de legislador, lo que se tradujo en "el buen regimiento y conservación de su señorío que era muy grande". La prevalencia del orden y la ley en Tetzcoco fue luego prolongada por su hijo y sucesor, Nezahualpilli (Zorita, 1999, pp. 339-343).

En algo que quizá fuera una proyección ideológica de la estructura legal de la monarquía católica, para Zorita (1999, p. 340) el gobernante tetzcocano ciertamente tenía la última palabra en la resolución de cualquier litigio, pero, según él, la impartición de justicia ordinaria dependía de un organismo integrado por "jueces" que deliberaban, oían y atendían las 
demandas de la gente. Esto hablaría de una "suprema magistratura", una especie de "Real Audiencia" indígena que desahogaba los casos contenciosos que se suscitarán en la población en general.

De dichos "jueces" se esperaba total rectitud en el ejercicio de sus cargos; admitir cohecho para favorecer a algún litigante, darse a otras prácticas deshonestas o beber alcohol eran conductas severamente penadas, que podían acarrearles la reprensión, la privación del oficio y el corte de cabello como señal de vilipendio. Una vez dictada la sentencia en su contra, no había posibilidad alguna de apelación (Zorita, 1999, pp. 343-344).

Respecto de la aplicación de la pena capital, Zorita (1999, pp. 347-348) afirma que era frecuente y que no sólo recaía sobre el directamente inculpado sino que también, en determinadas ocasiones, sobre sus cómplices o encubridores. $\mathrm{Y}$ en esto -de acuerdo con sus palabras-, había un "equilibrio", pues lo mismo podía afectar el estrato superior que a los hombres comunes o macehualtin. Así habla de uno de los hijos de Nezahualcóyotl que osó cometer adulterio con una de las concubinas de su padre; por la magnitud de su falta y a despecho de su elevada condición, se le sentenció a muerte (Zorita, 1999, p. 345).

$\mathrm{Al}$ parecer, éste no fue el único caso en el que un principal tuvo que tomar una decisión tan drástica en contra de un miembro de su propia estirpe. En Tlaxcala, en el período de la primera evangelización, la estrategia de los franciscanos, y del propio Hernán Cortés, consistió en alejar a los hijos de los 
nobles de sus familias, lo que naturalmente tuvo el rechazo de los padres. Gonzalo Acxotecatl, principal de Atlihuetzian, escondió a su hijo favorito, pero los otros vástagos lo denunciaron y finalmente tuvo que entregarlo. Luego de "convertirse" acusó a su padre de idolatría, por lo que Acxotecatl lo asesinó. El filicida fue juzgado por los españoles y sentenciado a muerte. Este hecho, aunado al anterior relatado por Zorita, sugiere que la educación de los pipiltin o nobles era rígida e inflexible, lo que quizá se prolongó, pervivió e incluso se reconfiguró en el período novohispano (Martínez Baracs, 2008, pp. 115-118).

\section{Nezahualcóyotl en el Espejo de Príncipes}

Acaso inspirado por las Relaciones Geográficas que en aquel entonces se elaboraban, pero también buscando algún reconocimiento a sus méritos y linaje, en 1582 Juan Bautista Pomar decidió poner a la Corona en conocimiento de los recursos y características principales de su región, así que ese mismo año la retrató en su Relación de Tezcoco (Pomar, 1975).

Pomar era natural de dicha ciudad, y siendo su padre español y su madre indígena, se lo catalogaba de "mestizo". Sin embargo, no puede decirse que se haya identificado ni con su raíz hispánica ni con la indígena tetzcocana en general, sino que su filiación e intereses se orientaban decididamente hacia el estrato nobiliario de este antiguo centro prehispánico (Inoue Okubo, 2007, pp. 62-63). Algo muy digno de tenerse en cuenta cuando se lee su obra. 
Para Pomar (1975, pp. 6-7), Nezahualcóyotl y su hijo fueron personajes "bienaventurados", que dieron "leyes y ordenanzas" a su gente, para que viviera conforme a razón y en policía. El dominio de ambos era absoluto: en sus manos estaba la vida y muerte de la población, pero jamás incurrieron en la tiranía, pues su comportamiento era justo y recto.

Si Zorita destacó el papel de Nezahualcóyotl como el fiel de la balanza que delegaba en sus representantes o jueces la administración general de justicia, Pomar lo aproxima a los bocetos morales de los manuales o "Espejos de príncipes", un género literario altamente cultivado en la Europa de aquella época, si bien la preocupación de tener "un buen gobernante" fue, y es, extensiva a todas las civilizaciones europeas y no europeas. En consecuencia, Nezahualcóyotl deviene en la Relación de Tetzroco en el ideal de gobernante, que no sólo es justo, sino también humilde; que es consciente de su naturaleza humana y sabe que su poder lo recibe de Dios, al que ama, teme y respeta. Se puede considerar que para el análisis de este argumento "Las fuentes son de inspiración, no de autoridad; sirven para proporcionar imágenes, episodios y personajes del pasado que, sacados de su articulación histórica hacen las veces de temas que se engarzan en una concatenación distinta a la concatenación espacio temporal en que se dan" (O'Gorman, 2007, p. 63). En cuanto a esto, desde luego, Pomar lo distancia hasta donde le es posible de la idolatría común de su pueblo, por eso muestra sus dudas y vacilaciones en torno a la existencia de las divinidades y subraya su convicción de que era un "engaño creer que unos bultos de palo y de piedra hechos por manos de hombres fuesen dioses" (Pomar, 1975, p. 24). Su 
práctica recurrente del ayuno, su clemencia y su justicia (Pomar, 1975, p. 23) bien hubieran podido hacer de él un gobernante cristiano que, para su desdicha, tuvo el mal tino de nacer, vivir y morir poco antes de que en su reino se conociese el evangelio. Sin embargo, se ha de considerar que tales atributos dados por los cronistas a Nezahualcóyotl, nuevamente ponen en relieve sus consideraciones sobre la historia y lo humano: "Los anacronismos, tan repugnantes a nuestro sentido de verdad, no resultan falsedades, porque no existen como tales anacronismos; y precisamente, el hecho de imaginar el pasado encarnado en las formas del presente es una manera simbólica y profunda de expresar ese sentimiento de identidad de las cosas humanas" (O'Gorman, 2007, p. 57).

No está de más afirmar que tantas virtudes habían de trasminarse forzosamente a su pueblo, ya que aunque idólatra, no estaba tan ciego ni desencaminado como otros, en la medida en la que no habían sido los tetzcocanos, sino los mexicas los inventores de los diabólicos sacrificios humanos (Pomar, 1975, p. 15). En este sentido, la construcción que se comienza a fraguar sobre la imagen modélica de Nezahualcóyotl contiene un fuerte intento de reivindicación del estado idolátrico de Tetzcoco que era necesario limpiar, pues, en cierta forma, manchaba la imagen de los descendientes de dicho centro prehispánico, entre los que se puede citar al propio Pomar y a Fernando de Alva Ixtlilxóchitl. 


\section{Nezahualcóyotl de cuerpo entero}

Unas décadas después de que Pomar escribiera su obra, Fernando de Alva Ixtlilxóchitl presentó una historia de salvación de corte precristiana acaecida en Tetzcoco, los tiempos que le correspondieron vivir no fueron los más estables y con un afán personal e histórico (Romero Galván, 2003, p. 362) redactó una compleja obra integrada por cinco relaciones muy particulares en las que registró información, a veces similar, a veces contradictoria, del protagonismo de Nezahualcóyotl.

Así, en la información registrada en uno de sus manuscritos: la Relación suscinta en forma de memorial de las historias de Nueva España y sus señorios hasta el ingreso de los españoles, cuya preocupación está enfocada en "traducir", según su propia interpretación, la historia original de los señores "de esta tierra" para uno de los virreyes de la Nueva España. En torno a esta cuestión, Edmundo O'Gorman agrega que quizá el propósito de esta relación haya sido "presentar al virrey al que iba dedicada, un breve relato de la historia antigua de México mostrando el ilustre y glorioso pasado de los antiguos monarcas de la tierra, entre los cuales figuran prominentemente los ascendientes del autor" (1975, p. 207). Coincidimos con O'Gorman sobre las intenciones de Alva Ixtlilxóchitl de obtener el favor real, pero consideramos, de igual forma, que no lo hace directamente, sino que antepone su preocupación de "interpretar" una historia poco clara ante ojos extraños, de "traducirla" para hacerla comprensible y legible, 
pues "para quien lo entiende es tan claro como nuestras letras" (Alva Ixtlilxóchitl, 1975a, pp. 412-413).

En este tenor, Alva Ixtlilxóchitl (1975a, pp. 404-407) elabora una descripción de Nezahualcóyotl, en la que sobresalen los atributos siguientes: valeroso, por recuperar su centro después de haber sido despojado; sabio, por reconocer que existió un solo dios, muy a pesar de ser idólatra por faltarle la ley evangélica; justiciero, porque "castigaba con grandísimo rigor y muerte los pecados"; misericordioso, especialmente, con los pobres, enfermos, viudas y viejos y hombre de gran gobierno, por crear cuatro consejos y por haber traído a los mejores artífices hasta Tetzcoco.

Pero no es sino hasta la última de las cinco relaciones del referido cronista tetzcocano, la Historia de la nación chichimeca, en donde Nezahualcóyotl adquiere mayor importancia y se perfila como figura central y protagónica de distintos episodios medulares que acontecieron en el posclásico tardío en la cuenca de México. El relato abarca desde la trágica etapa juvenil del gobernante, misma en la que ve morir a su padre a manos de sus enemigos tepanecas de Azcapotzalco, la huída que emprendió, las múltiples ocasiones en las que escapó de ser capturado, la pérdida de su sede de poder y las alianzas que entabló para recuperar su centro y, una vez recuperado, darle un nuevo orden.

En efecto, Nezahualcóyotl aparece como mediador y constructor del nuevo orden tras ocasionar la caída de Azcapotzalco [Fig. 1], y su figura no es opacada ni siquiera por el buey tlatoani tenochca: Izcóatl. Es a partir de este acto de 
recuperar Tetzcoco que Nezahualcóyotl se vuelve gobernante legítimo y adquiere el título de chichimeca tecubtli (señor chichimeca). Entre las primeras acciones que emprende, reanuda alianzas con antiguos centros vecinos, restituyéndoles a sus anteriores gobernantes, sin importar que durante la contienda contra Azcapotzalco le hayan dado la espalda, pues como señala Alva Ixtlilxóchitl, esta manera de proceder reveló "su nobleza y gran valor, y no tener memoria de hombre tirano, con que engrandeció la memoria de sus antepasados" (1975b, p. 89).

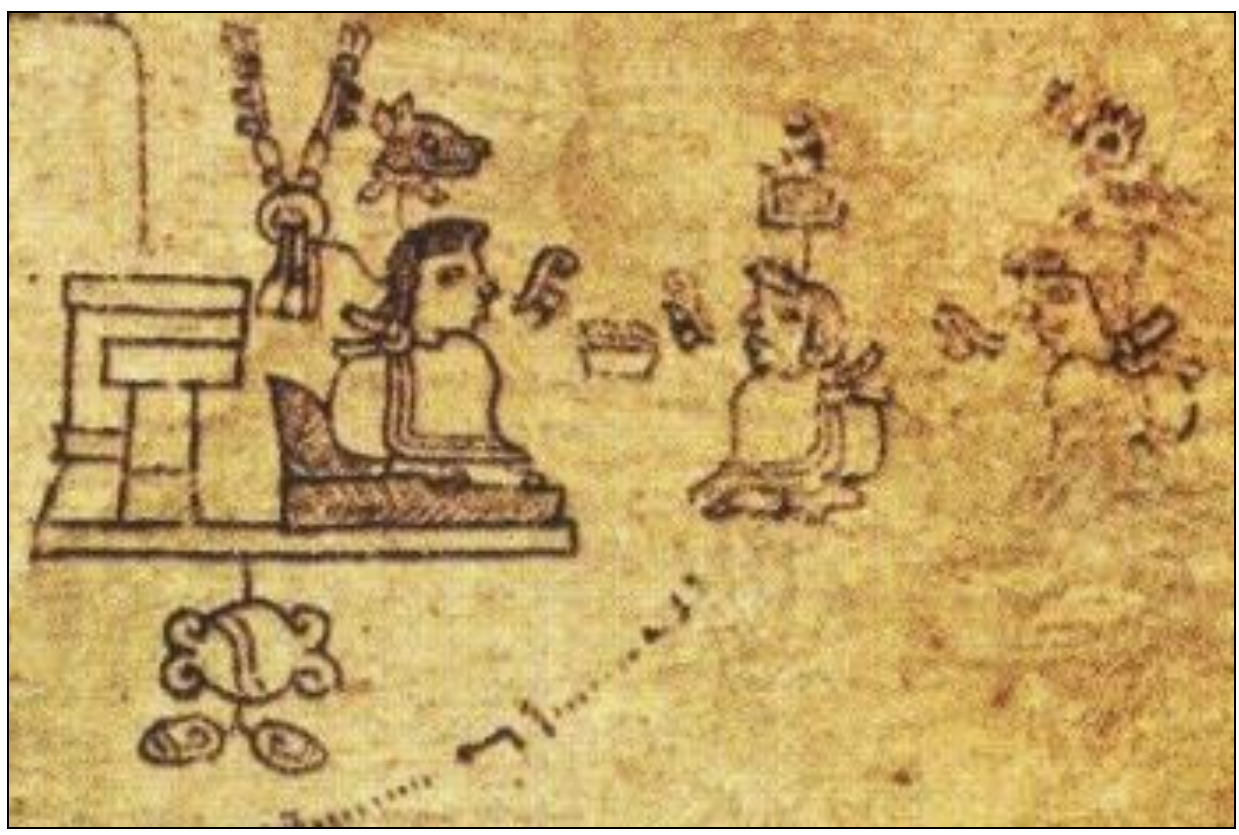

[Figura 1] Una vez recuperado Tetzcoco, Nezahualcóyotl dicta las nuevas disposiciones. Fragmento de la Lámina X en Códice Xólotl, México, Universidad Nacional Autónoma de México-Instituto de Investigaciones Históricas, 1980. 
Es en este punto, donde la nueva organización propuesta por el gobernante de Tetzcoco se torna ejemplar, proyectándose no solo en las acciones y decisiones tomadas por Nezahualcóyotl, sino en la espacialidad misma, al crear un edificio, "palacio", que le servía de vivienda y en el que consignó una zona específica para un supuesto "tribunal" desde el que se celebraban audiencias públicas y se determinaban y confirmaban sentencias de muerte (Alva Ixtlilxóchitl, 1975b, pp. 93-95). En torno a esta descripción es relevante señalar que Alva Ixtlilxóchitl tuvo a la vista pictografías, que quizá le fueron explicadas, y que le permitieron detallar este recinto, pero que resultan imposibles de contrastar con los escasos restos arqueológicos que sobreviven.

Otras acciones importantes que emprendió Nezahualcóyotl y que Alva Ixtlilxóchitl consignó fueron la creación de lugares de recreación como bosques y jardines (Alva Ixtlilxóchitl, 1975b, pp. 114-116), los cuales también reflejan complejas obras hidráulicas; la elaboración de "cantos" (Alva Ixtlilxóchitl, 1975b, pp. 132-133) que para el cronista referido se equiparan a "profecías" que anunciaron el "aumento de vicios" y que, probablemente, serán el inicio de la denominación de un "rey poeta".

En este sentido, podemos percibir, a partir del relato de Alva, la proyección de una imagen espectacular y todapoderosa, es decir, al gobernante que todo lo puede y en todo lugar está, su presencia constante es tal que lo convierte en el gran Hacedor: de orden, de normas, de instituciones, desde su trágica etapa juvenil hasta sus últimos días. Es el 
cronista que más datos proporciona sobre el andar de un gobernante que ve morir a su padre a manos de sus enemigos y que emprende la huída para evitar la muerte. En resumen, es también el mayor biógrafo y panegirista de este ejemplar gobernante, labor que se refleja en el significado que proporciona del segundo nombre a Nezahualcóyotl: Acolmiztli, "que quiere decir, brazo de león, porque con su valor y brazo sujetó y recobró casi toda la tierra que había muchos años que estaba rebelada con las tiranías de los reyes de Azcaputzalco" (Alva Ixtlilxóchitl, 1975c, pp. 439-440).

Tan elocuente descripción de la ejemplaridad de Nezahualcóyotl, termina opacando a uno de los parientes del referido gobernante: Carlos Ometochtzin, quien había sido quemado por las autoridades novohispanas por "hereje dogmatizador". El silencio que este cronista guarda sobre tan importante incidente, nos hace pensar que su discurso se orientó hacia el lado de la balanza que pudiera beneficiar su situación, pues no hay que olvidar que Alva Ixtlilxóchitl se preciaba de ser descendiente de la estirpe tetzcocana.

\section{Un "soberano" indígena asimilado a la historia de la cristiandad}

Algunas de las ideas de este apartado proceden de la ponencia "Los paradigmas indígenes de Torquemada" (Battcock \& Escandón, 2014), misma que traemos a ocasión de continuar la revisión de la figura histórica de Nezahualcóyotl. El libro segundo de la Monarquía Indiana del cronista 
franciscano Juan de Torquemada, recupera la memoria histórica antigua de México. Ahí, en un tapiz narrativo homogéneo, se entretejen los mitos, las creencias, las prácticas $\mathrm{y}$ las historias que articularon el pasado del mundo tetzcocano con el del resto de los pueblos de la cuenca de México. A partir de registros escritos o pictográficos, y a veces orales, Torquemada (1975, vol. 1, p. 177 y p. 208) confecciona lo que él tiene por la "verdadera" historia, aventuras y desventuras de Nezahualcóyotl. Con esta pretensión de certidumbre y autenticidad documental se distancia y hasta descalifica lo asentado por otros prestigiosos autores, como José de Acosta.

En la urdimbre histórica de Torquemada no sólo hay recuperación fáctica o memoria colectiva, sino también y, muy notoriamente, una construcción a partir de la visión providencialista de la historia que le es propia. De ahí que el autor crea encontrar en el pueblo tetzcocano y en su principal gobernante-héroe (Lesbre, 2000, pp. 21-55), Nezahualcóyotl, a los virtuosos heraldos del advenimiento evangélico, a pesar de que ni los unos ni los otros habían escuchado jamás la palabra divina.

De esta suerte, Nezahualcóyotl -a quien ya exaltan suficientemente las fuentes tetzcocanas que empleó Torquemada- se convierte en el depositario o receptáculo de todas las cualidades de un modélico príncipe cristiano. Sin duda, en este gran lienzo del gobernante tetzcocano mucho pudo influir la visión de Juan Bautista Pomar, a quien Torquemada dice haber conocido, y cuya Relación de Tetzcoco utilizó (Carrera Stampa, 1971, pp. 212-213). 
Su valor, su ánimo bélico, su sabiduría, su piedad, su prudencia y su justicia lo hacían ser amado por su pueblo. Lamentablemente, los méritos de este ejemplo de perfecciones se eclipsaban por un único factor: la idolatría (Torquemada, 1975, p. 206). Pero aun esto podía ser matizado y, hasta cierto punto, exculpado, porque, del mismo modo que Pomar, el cronista religioso trae a colación aquella expresión atribuida al señor de Tetzcoco, en el sentido de que los dioses no eran sino "maderos y palos" que no merecían adoración, sino que movían a risa. Y todo esto se corroboraba con las órdenes que, según Torquemada (1975, p. 241), dio luego para que no se realizaran más sacrificios humanos, sino sólo de aves, animales o plantas.

Por otra parte, acaso para conferirle inteligibilidad ante sus lectores europeos, Nezahualcóyotl es continuamente equiparado con personajes de la historia clásica o de la Biblia, especialmente del Antiguo Testamento. Así, la gente no podía mirarlo cara a cara, como a los reyes babilonios; su inclinación por la música y la composición eran paralelos a los del emperador Nerón y hasta su único pecado: urdir la muerte de un marido para quedarse con su esposa, encuentra reflejo en la acción del rey David contra Urías para apoderarse de su mujer, Betsabé. Estas equiparaciones se deben principalmente a la lectura que el propio Torquemada hace al insertar a Nezahualcóyotl dentro de los tiempos de la cristiandad, ubicándolo en las eras anteriores a los del conocimiento del evangelio y la redención cristiana. Puede decirse que "Los hechos quedan subordinados a la gran verdad de la historia. Los anacronismos, las contradicciones circunstanciales, las 
falsas atribuciones ¿Qué importan? Pertenecen a la infraestructura de lo temporal" (O'Gorman, 2007, p. 65).

La versión de Juan de Torquemada sugiere que, aun siendo un gentil y desconociendo la verdadera fe, Nezahualcóyotl ya intuía o barruntaba la cercanía de la luz del cristianismo. Y como es el único gobernante de la historia del México antiguo al que se representa de tal modo, tal vez podría entenderse que el personaje se ofrece como una figura de tránsito entre la era del politeísmo y la del evangelio.

La efigie del legítimo señor de Tetzcoco tiene en el relato su contrapartida o némesis: se trata de Maxtla, primer gobernante de Coyoacán y posteriormente de Azcapotzalco. Los rasgos distintivos de este "mal príncipe" son la ilegitimidad, la cobardía, la traición, la injusticia, la inmoralidad y -caso muy grave en un gobernante- la ineptitud para establecer alianzas con otros centros.

Juntos, héroe y antihéroe, sirven a Torquemada en una doble vertiente: primero, como un binomio dicotómico para conducir al lector por los vericuetos y dificultades del gobierno de los centros en la cuenca de México, por ejemplo, el problema sucesorio y la fragilidad de las hegemonías de las ciudades en el período posclásico. $\mathrm{Y}$, en el otro extremo, dentro de la estrategia narrativa, tal equiparación de los contrarios puede ser también una proyección del esquema agustiniano de la historia, es decir, la dramática lucha cósmica entre el bien y el mal, que deberá concluir con el triunfo definitivo del primero. 
Así parecería confirmarlo la fase inmediata a la derrota de Azcapotzalco, a manos de los tenochcas y de Nezahualcóyotl, y a la muerte o desaparición de Maxtla, pues, en consecuencia a este acto, el señor tetzcocano inicia en su centro una serie de reformas administrativas, judiciales, económicas, militares y religiosas que, al tiempo que marcan el despunte de la prevalencia de Tetzcoco, también -se quiera o no-, evocan nuevamente los libros históricos de los Reyes, en el Viejo Testamento, que tratan de los gloriosos reinados de David y Salomón. Casualmente, dos "monarcas" con fama de sabios.

En la presentación de sus modelos indígenas, Torquemada marca un parteaguas; hay un "antes" y un "después" que, obviamente, se refieren a la llegada del evangelio a tierras americanas, tal como en la historia del mundo estas fases las señala el nacimiento de Cristo. Así pues, en su narración sobre los "príncipes" indígenas, Nezahualcóyotl y Maxtla, el cronista parece apelar a la historia de Israel previa a la venida del Mesías, estrategia narrativa que se presenta como una interesante continuidad de pensamiento de la escritura de la historia en la edad media: "En la Redención se alojan y encuentran fundamento, no lógico, sino de una experiencia vital profunda y decisiva, las dos dimensiones de la concepción histórica medieval: la identidad de lo humano y la diferencia constitutiva de las edades. La verdad histórica sólo es verdad en tanto que expresa la subordinación del proceso histórico a la Redención" (O’Gorman, 2007, p.65). 


\section{Notas finales}

Hemos hecho un seguimiento de las bases historiográficas que fueron delineando la figura de Nezahualcóyotl como uno de los máximos exponentes del buen gobierno y la recta administración de la justicia en Tetzcoco. Las reiteradas referencias a sus nobles atributos es común denominador en las cuatro fuentes aquí analizadas. Sin embargo, como se ha señalado, parece lógico que para un letrado español, como lo era don Alonso de Zorita, la imagen del gobernante -máximo dispensador de justicia en el imaginario político hispánicodebía ir convenientemente acompañada de un gran tribunal, de un cuerpo de jueces capaces de hacer valer las leyes de su señor y de dar a cada uno de sus súbditos lo que le correspondía en derecho.

En contrario, para Pomar, y después para Fernando de Alva Ixtlilxóchitl, quizás por pertenecer a la misma "casa real tetzcocana" y que quizá se hayan conocido personalmente, los límites de acción de Nezahualcóyotl rebasaron el esquema de un gobernante modelo, encaminándolo así a otra concepción cercana a la divinización. Al nutrirse de estas fuentes, el fraile Torquemada continuó con esta apreciación.

¿Qué sabemos sobre Nezahualcóyotl? ¿Habría una tradición tetzcocana antigua que pregonaba su fama de buen señor, de recto gobernante, de ensachador de su reino? Es muy probable, pero será motivo de otro trabajo delinear la figura que representó para sus gobernados y sus descendientes. 
Finalmente, nos queda señalar que las indumentarias e insignias que se le colocaron a Nezahualcóyotl en época colonial, serán puestas en escena siglos más tarde por el ilustrado José María Vigil Orozco (1876), pero con renovados bríos, ahora como "héroe patriótico" que sirvió para fortalecer con el ejemplo la identidad nacional mexicana decimonónica (Ríos de la Torre, 2009, pp. 131-149) [Fig. 2].

$\mathrm{Y}$ es que el rescate del tiempo pasado tiene obvias dimensiones y usos presentes; entre los principales, el de forjar un espejo donde el grupo en cuestión pueda reconocerse y, al mismo tiempo, "actualizar" la memoria, porque es en el ahora y el aqui donde se formulan los deseos para el futuro. La proyección de dichos anhelos sobre la pantalla de un pasado espléndido, permite el rebote de un eco, que llega al presente para traducirse en reclamos de justicia- y que también puede alcanzar el futuro, en forma de esperanza de reparación.

Para todos los grupos humanos construir una identidad colectiva es una empresa de vital importancia. Lo es porque proporciona arraigo, porque engendra tradiciones, valores, costumbres, simbolismos, formas de ser y de estar que, con el paso del tiempo, echan raíces, se hacen historia y forman parte de un legado que pasa de generación en generación (Le Goff, 1991, p. 131; Añón, 2012). Desde entonces, y con el correr de los años, ajustándose a circunstancias específicas, el gobernante tetzcocano se mantiene vigente, incluso en nuestros días, de forma modélica. 


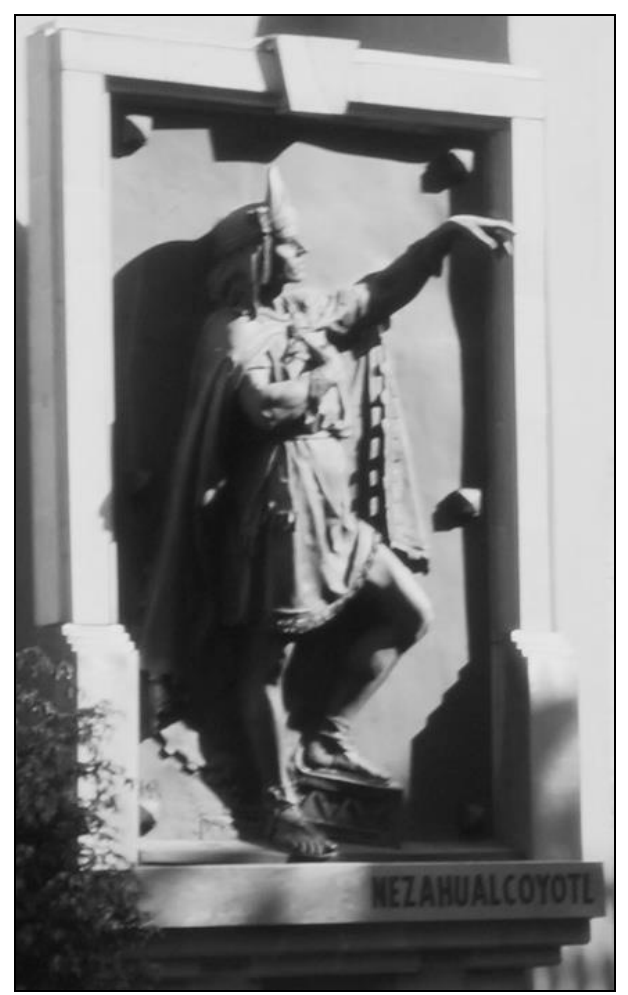

[Figura 2] Escultura de Nezahualcóyotl realizada por el escultor mexicano Jesús Fructuoso Contreras en 1888. Fotografía tomada por Maribel Aguilar el 12 de febrero de 2013. 


\section{Referencias Bibliográficas}

Ahrndt, W. (1999). Alonso de Zorita: Un funcionario colonial de la Corona española”. A. d. Zorita. Relación de la Nueva España (Vol. 1). México: CONACULTA.

Alva Ixtlilxóchitl, F. d. (1975a). "Relación suscinta en forma de memorial de las historias de Nueva España y sus señoríos hasta el ingreso de los españoles". Obras históricas (Vol. 1). México: Universidad Nacional Autónoma de México-Instituto de Investigaciones Históricas.

Alva Ixtlilxóchitl, F. d. (1975b). "Historia de la nación chichimeca”. Obras históricas (Vol. 1). México: Universidad Nacional Autónoma de México-Instituto de Investigaciones Históricas.

Alva Ixtlilxóchitl, F. d. (1975c). "Compendio histórico del reino de Texcoco". Obras históricas (Vol. 1). México: Universidad Nacional Autónoma de México-Instituto de Investigaciones Históricas.

Añón, V. (2012). La palabra despierta. Tramas de la identidad y usos del pasado en Crónicas de la conquista de México. Buenos Aires: Corregidor.

Battcock, C., \& Escandón, P. (2014). "Los paradigmas indígenas de Torquemada". Simposio Mundus Novus de la modernidad ibero-atlántica: encuentros y desencuentros entre misioneros, indígenas y esclavos en las Américas. XVII Congreso Internacional de AHILA. Berlín, Alemania.

Carrera Stampa, M. (1971). "Historiadores indígenas y mestizos novohispanos". Revista española de Antropología americana (6).

Herrera Maza, M. d., López Austin, A., \& Martínez Baracs, R. (2013). "El nombre náhuatl de la Triple Alianza". Estudios de Cultura Náhuatl, 46, 8-35. 
Inoue Okubo, Y. (2007). "Crónicas indígenas: una reconsideración sobre la historiografía novohispana temprana”. D. Levin Rojo \& F. Navarrete. Indios, mestizos y españoles. Interculturalidad e historiografía en la Nueva España. México: Universidad Autónoma MetropolitanaAzcapotzalco, Universidad Nacional Autónoma de MéxicoInstituto de Investigaciones Históricas.

Le Goff, J. (1991). El orden de la memoria, el tiempo como imaginario. Barcelona: Paidós.

Lesbre, P. (2000). "Nezahualcóyotl, entre historia, leyenda y divinización”. F. Navarrete \& G. Olivier. El héroe entre el mito y la historia. México: Universidad Nacional Autónoma de México-Instituto de Investigaciones Históricas, Centro Francés de Estudios Mexicanos y Centroamericanos.

Martínez Baracs, A. (2008). Un gobierno de indios: Tlaxcala, 1519-1750. México: Fondo de Cultura Económica, Centro de Investigaciones y Estudios Superiores en Antropología Social, Colegio de Historia de Tlaxcala.

O’Gorman, E. (1975). "Bibliografía razonada de Alva Ixtlilxóchitl”. F. Alva Ixtilxóchitl. Obras históricas (Vol. 1). México: Universidad Nacional Autónoma de México-Instituto de Investigaciones Históricas.

O'Gorman, E. (2007). "La conciencia histórica en la Edad Media”. E. O’Gorman. Historiología: teoría y práctica. $1^{\mathrm{a}}$ reimpresión. Selección e introducción de Álvaro Matute. México: Universidad Nacional Autónoma de México.

Pomar, J. B. (1975). Relación de Tezcoco. México: Biblioteca Enciclopédica del Estado de México.

Ríos de la Torre, G. (2009). "El nacimiento de un héroe: El rey poeta Nezahualcóyotl”. Tema y Variaciones de Literatura (32).

Romero Galván, J. R. (2003). “Fernando de Alva Ixtlilxóchitl”. J. R. Romero Galván. Historiografía mexicana. Historiografía 
novohispana de tradición indígena (Vol. 1). México: Universidad Nacional Autónoma de México-Instituto de Investigaciones Históricas.

Ruíz Medrano, E. (1999). "Proyecto político de Alonso de Zorita, oidor en México”. A. d. Zorita. Relación de la Nueva España. México: CONACULTA.

Torquemada, J. d. (1975). Monarquía indiana de los veinte y un libros rituales y monarquía indiana, con el origen y guerras de los indios occidentales, de sus poblazones, descubrimiento, conquista, conversión y otras cosas maravillosas de la mesma tierra firme (Vol. 1). México: Universidad Nacional Autónoma de México-Instituto de Investigaciones Históricas.

Vigil Orozco, J. M. (1876). “Nezahualcóyotl”. Hombres ilustres. México: Ediciones Zarco.

Zorita, A. d. (1999). Relación de la Nueva España. México: CONACULTA. 